\title{
EDUCAÇÃO MUSICAL E INOVAÇÃO PEDAGÓGICA: O CASO DA CREATIVE MUSIC DE SATIS COLEMAN ${ }^{1}$
}

\author{
Music education and pedagogical \\ innovation: the case of Creative Music by \\ Satis Coleman
}

\author{
Educación Musical y innovación pedagógica: \\ el caso de la Creative Music de Satis \\ Coleman
}

\author{
TAMYA MOREIRA \\ Universidade Federal de São Carlos \\ tamya.moreira@gmail.com
}

\begin{abstract}
Resumo: O presente artigo tem como objetivo a apresentação de aspectos fundamentais da Creative Music, salientando sua coerência com o contexto de inovação pedagógica em que foi desenvolvida e seu caráter de pioneirismo - sobretudo na abertura para a participação das crianças e para as práticas criativas. O termo Creative Music refere-se ao trabalho da educadora musical estadunidense Satis Coleman iniciado na década de 1910 com crianças em um estúdio particular em Washington D.C. e, posteriormente, ampliado na Lincoln School, escola-laboratório do Teachers College da Columbia University, entre os anos de 1919 e 1942. Coleman trabalhou na educação básica e na formação de professores da instituição, além de produzir obra numerosa sobre sua atuação pedagógica. Apesar de pouco estudada na atualidade, sua proposta teve difusão internacional nas décadas de 1920, 1930 e 1940, chegando ao Brasil através dos escritos de João Caldeira Filho (1945, s.d.). A análise de sua obra e de sua influência soma esforços na construção de discursos historiográficos que contemplem as contribuições de mulheres para a inovação didática em educação musical.
\end{abstract}

Palavras-chave: Satis Coleman. Práticas criativas. Construção de instrumentos musicais.

\begin{abstract}
This article aims to present the fundamental aspects of Creative Music, emphasizing its coherence with the context of pedagogical innovation in which it was developed and its pioneering character - especially related to the participation of children and creative practices. The term Creative Music refers to the work of the American music educator Satis Coleman started in the 1910s with children in a private studio in Washington D.C. and later expanded at Lincoln School, a laboratory school of the Teachers College of Columbia University, between 1919 and 1942. Coleman taught music to the children and worked in teacher training at the institution, as well as producing numerous books and articles on her pedagogical proposal. Although little studied at present, her proposal had international diffusion in the 1920s, 1930s and 1940s, arriving in Brazil through the writings of João Caldeira Filho (1945; n.d.). The analysis of her work and its influence add efforts in the construction of historiographical discourses that contemplate the contributions of women to didactic innovation in musical education.
\end{abstract}

Keywords: Satis Coleman. Creative practices. Musical instruments making.

Resumen: Este artículo presenta aspectos fundamentales de la Creative Music, enfatizando su coherencia con el contexto de innovación pedagógica en el que se desarrolló y su carácter pionero, especialmente en la apertura a la participación de los niños y a las prácticas creativas. El término Creative Music se refiere al trabajo del educador musical estadounidense Satis Coleman, que comenzó en la década de 1910 con niños en un estudio privado en Washington D.C. y que más tarde se amplió en la Lincoln School, la escuelalaboratorio del Teachers College de la Universidad de Columbia, entre los años 1919 y 1942. Coleman trabajó en educación básica y formación de profesores en la institución, así como en la producción de numerosos escritos sobre su acción educativa. Aunque poco estudiada en la actualidad, su propuesta tuvo difusión internacional en las décadas de 1920, 1930 y 1940, llegando a Brasil a través de los escritos de João Caldeira Filho (1945; s.f.). El análisis de su obra y su influencia suman esfuerzos en la construcción de discursos historiográficos que contemplan los aportes de las mujeres a la innovación didáctica en la educación musical.

Palabras clave: Satis Coleman, prácticas creativas, construcción de instrumentos musicales.

${ }^{1}$ A pesquisa que deu origem ao artigo foi desenvolvida com financiamento da Fundação de Amparo à Pesquisa do Estado de São Paulo (Fapesp) e Coordenação de Aperfeiçoamento de Pessoal de Nível Superior (Capes), processo n ${ }^{\circ}$ 2015/01978-0. 


\section{INTRODUÇÃO}

$\mathrm{Na}$ edição de janeiro de 1945 da Revista Brasileira de Estudos Pedagógicos (RBEP), o sétimo número do então recém-lançado periódico, temos o primeiro texto da publicação em que a educação musical é tema central $^{2}$. Assinado por João Caldeira Filho, o artigo tinha por título "Educação musical infantil" e ocupava três páginas da seção Através de Revistas e Jornais, pois tratava-se de um texto replicado do jornal O Estado de S. Paulo.

No início de seu texto, Caldeira Filho (1945) apresenta o assunto focalizado: a educação musical de crianças pequenas, entre três e seis anos de idade. $\mathrm{O}$ autor relata que educadoras em formação o procuraram pela consciência da falta de preparo para trabalhar com tal faixa etária, o que o autor considerou muito positivo. Essa consciência apontava para a possibilidade de formulação de modos de ensinar que não necessariamente passavam pelo que chamou de "plano rígido dos conservatórios" (1945, p. 120), nem pela aula específica de piano. Além de formação pedagógica e convívio com crianças, o autor defende que seria preciso conhecer o que vinha sendo feito na área, e então apresenta a seguinte referência: "O que de melhor conheço neste sentido é a chamada "Música Criadora", da professora norte-americana Satis N. Coleman (Creative Music for Children, G. P. Putnam's Sons, New York and London)" (Caldeira Filho, 1945, p. 120).

No livro indicado pelo autor, o primeiro de muitos publicados por Coleman, lemos uma apresentação de G. Stanley Hall (in Coleman, 1922) onde o psicólogo declara que tal publicação marcaria época em pedagogia musical. Além de ter produção bibliográfica profusa, Coleman ocupou cargos em uma das instituições educacionais mais importantes de sua época, a Columbia University, centro destacado no cenário internacional de movimentos pedagógicos progressistas. Suas ideias pedagógico-musicais circularam internacionalmente nas décadas de 1920, 1930 e 1940, sendo observadas não apenas nos esforços de divulgação de Caldeira Filho no Brasil, mas também em contexto europeu. Na imprensa pedagógica estadunidense, destacadamente aquela ligada ao movimento Progressive Education, a proposta de Coleman suscitava discussões, engajando adeptos e críticos. Contudo, apesar de seu protagonismo no campo em seus anos de atividade, seu trabalho é pouco conhecido e discutido nos dias atuais.

O presente artigo tem por objetivo expor alguns principios da Creative Music, sua pertinência no contexto em que se desenvolveu e sua validade em discussões sobre os problemas contemporâneos da educação musical. O estudo apresentado baseia-se em pesquisa em fontes primárias e

2 O tema já havia sido abordado de maneira indireta e sucinta no segundo número da revista, de agosto de 1944, apenas como parte dos conteúdos da ata da I Conferência de Ministros e Diretores de Educação das Repúblicas Americanas. 
secundárias, mais especificamente alguns dos livros assinados pela educadora, artigos de imprensa pedagógica de sua autoria e/ou implicados no debate sobre seu trabalho, bem como produção científica posterior. Os princípios de sua proposta aqui focalizados serão a construção de instrumentos e a abertura para a participação e as práticas criativas das crianças, temas em evidência também na educação musical contemporânea. Seu trabalho será contextualizado no que diz respeito ao pano de fundo epistemológico e à sua coerência com o movimento pedagógico onde estava inserido, a Progressive Education. Assim, pretende-se dar a ver o caráter inovador de Coleman em seu cenário e os aspectos de sua proposta pertinentes para a reflexão sobre educação musical no presente. Pretendese, ainda, colaborar para um alargamento das referências sobre inovação em educação musical infantil, visto que a representação deste quadro no início do século XX ainda se restringe, correntemente, aos chamados métodos ativos. Não se intenta elaborar uma critica a tais métodos, mas defender que o estudo da Creative Music de Coleman possibilita ultrapassar este quadro predominantemente europeu, masculino e protagonizado por compositores que atuaram principalmente em escolas de música.

\section{ORIGEM E DESDOBRAMENTOS}

O termo Creative Music é adotado em ocasião da entrada de Satis Coleman (1878 - 1961) no corpo docente da Lincoln School, escolalaboratório do Teachers College da Columbia University, em Nova York. O título refere-se não apenas à sua proposta, mas também à disciplina que Coleman assume na instituição em 1919. Os fundamentos de seu trabalho, entretanto, já vinham sendo experimentados há alguns anos em um estúdio particular em Washington D.C., onde começou a dar aulas de música para crianças $^{3}$.

Em 1922, portanto, três anos após a chegada à Lincoln School, o livro Creative Music for Children é publicado nos Estados Unidos e na Inglaterra. Neste livro é exposta a gênese do trabalho nos anos de aulas particulares e a origem do termo Creative Music é elucidada. Esse termo viria a figurar em livros subsequentes da educadora e nas menções ao seu trabalho na imprensa pedagógica da época. No prefácio, a autora atribui o termo à Miss Emily Barnes ${ }^{4}$ :

\footnotetext{
${ }^{3}$ A própria autora, ao apresentar seu trabalho como uma abordagem experimental, entra em contradição sobre a data exata de início. Em texto que trata de sua trajetória publicado entre 1932 e 1933, Coleman informa que seus primeiros experimentos haviam começado há 17 anos, logo, entre 1915 e 1916 (Coleman, 1932/1933). Contudo, no livro dedicado a expor a gênese de sua proposta, Coleman afirma que o experimento propriamente dito se iniciou em outubro de 1918 (Coleman, 1922). O estúdio muda de Washington D. C. para Nova York no ano de 1919 (Coleman, 1932/1933).

${ }^{4} \mathrm{Na}$ lista de professores publicada em The Lincoln School of Teachers College: a descriptive booklet (Columbia University, 1922), lemos que a professora do sexto ano chamava-se Emma A. Barnes, não Emily, como escreve Coleman (1922).
} 
Depois de observar o experimento em meu estúdio e na escola, ela considerou apropriado o nome Creative Music para cobrir todas as fases do trabalho: a construção de instrumentos, a criação musical e poética, a performance instrumental, o canto e a dança; e é neste sentido que usei o termo ao longo do livro (Coleman, 1922, p. ix)

Em artigo publicado na revista Progressive Education dez anos mais tarde, Coleman (1932/1933) nos oferece uma narrativa de sua trajetória e adiciona uma justificativa para o termo, associando sua proposta pedagógica ao estímulo à criatividade:

Durante o primeiro inverno de experimentos na Lincoln School, a professora do sexto ano, vendo como seus alunos eram estimulados ao trabalho original por um impulso interno, disse um dia: "Este tipo de música torna as crianças criativas, então vou chamá-la de creative music a partir de agora". Isso foi em 1919, antes que a expressão creative activity tivesse se tornado um slogan popular (Coleman, 1932, p. 28).

O trabalho exposto no livro de estreia centrava-se no experimento dos primeiros anos em estúdio, com crianças de três a nove anos de idade, em aulas individuais e em grupo. A assunção do posto na Lincoln School trouxe o desafio de adaptar os princípios de seu trabalho à realidade da escola regular. Segundo Coleman (1932/1933), seus objetivos naquele momento foram os seguintes: (a) observar se sua abordagem seria também adequada a grupos mais numerosos, (b) se seria praticável dentro da estrutura de um programa institucional e (c) se as crianças continuariam interessadas ao longo do percurso escolar.

Os desdobramentos da adaptação parecem ter sido bem-sucedidos, visto que em 1925, seis anos depois de iniciar o ensino de Creative Music na escola-laboratório, Coleman assume também a formação de professores e supervisores de música no Teachers College da mesma universidade, e permanece em ambas as funções até 1942 (Volk, 1996). Os anos de atuação são também de grande atividade como autora de livros e artigos em revistas, principalmente no periódico Progressive Education, publicação de associação estadunidense homônima que congregava educadores envolvidos em movimento pedagógico experimental.

Destaca-se, entre suas publicações, o livro $A$ children's symphony, publicado em 1931 como parte de seu doutorado junto à universidade. Neste livro, Coleman relata a composição coletiva de uma sinfonia pelas crianças - a terceira que já haviam produzido sob sua orientação - e trata de aspectos da educação musical em contexto escolar, especialmente, a prática instrumental em grupo. Há ainda detalhes dos procedimentos metodológicos de seu estudo, como testes e entrevistas, visto que era um texto de cunho científico. A ênfase na participação das crianças é explicitada 
no subtitulo do livro, a saber: With the themes composed entirely by the children, and played by them on instruments of their own making and other simple instruments.

O livro A children's symphony é ainda um documento importante pois, além de dar a ver o pioneirismo de Coleman e os desdobramentos de sua atuação em ambiente escolar, exprime também uma tensão existente no campo à época. Há, no livro, um capítulo de título "Implicações", cujo primeiro texto é "Questões que podem ser levantadas" (Coleman, 1931, p. 99). Em tom defensivo, a educadora coloca questionamentos aos quais estaria sujeita. Dentre os muitos questionamentos levantados por ela, dois concernem ao tema da atividade composicional de crianças, a saber: "Não seria um desperdicio de tempo para as crianças aprenderem suas próprias composições? Ou aquelas de outras crianças?" [...] "É realmente produtivo para as crianças dedicarem seu tempo ao aprendizado de uma sinfonia feita com seus próprios temas, ou outra sinfonia não escrita por um grande compositor?" (Coleman, 1931, p. 102).

A promoção de atividades criativas, bem como a construção de instrumentos pelas próprias crianças, são dois pontos fundamentais da proposta de Coleman e serão abordados nas seções seguintes. Antes, faz-se necessário salientar que a grande influência da Creative Music no cenário do entreguerras não se deu sem conflitos. A proposta de Coleman, quando divulgada no exterior, era apresentada de maneira muito positiva, se não como um exemplo a ser seguido de maneira direta e integral, ao menos tomado como inspiração. Isso pode ser observado nos textos de Caldeira Filho em São Paulo (1945, s.d) e em meio a vários artigos da revista francesa La Nouvelle Éducation, sobretudo em produção de Madeleine Guéritte e como influência para Margaret James na Inglaterra. Nos Estados Unidos, entretanto, a Creative Music congregava educadores cujas práticas eram fundamentadas em seus principios - como David Dushkin $(1931,1933)$ e Edith Potter (1931, 1932a, 1932b) - e, ao mesmo tempo, era alvo de críticas contundentes - como as proferidas por Thomas Surette $(1930,1932)$.

O início da década de 1930 parece ter sido o momento de maior tensão entre os entusiastas e críticos do trabalho de Coleman. Em artigo da revista Progressive Education já evocado aqui, onde a educadora apresenta um histórico de sua proposta (Coleman, 1932/1933), lemos uma breve introdução assinada pela editora - à época, Ann Schumaker. O texto é anunciado como uma oportunidade para que Coleman esclarecesse alguns mal-entendidos relacionados à Creative Music que vinham ganhando espaço entre os atores da área. Segundo Coleman (1932/1933), a proposta gerava apreciações distintas já na ocasião de sua primeira divulgação, no livro de 1922. Entre professores, Creative Music for Children havia sido muito bem aceito por alguns e visto com desconfiança por outros; entre pais e mães, a resposta havia sido massivamente positiva; e, entre supervisores, o livro não havia suscitado interesse. Sobre este último grupo, ela atribui a falta de 
abertura a três fatores: (a) alguns consideraram a proposta nonsense; (b) outros acreditaram que o trabalho seria impraticável na escola, pela atenção e pelo tempo requeridos, e (c) em suas palavras: "talvez muitos deles estejam tão fundamentados em procedimentos convencionais que acabem por considerar qualquer interferência como uma heresia" (Coleman, 1932 / 1933, p. 28). Vejamos, na sequência, alguns pontos fundamentais dessa abordagem em educação musical.

\section{CREATIVE MUSIC: CONSTRUÇÃO DE INSTRUMENTOS E PRÁTICAS CRIATIVAS}

Visto que Satis Coleman atuou por mais de duas décadas como educadora e produziu uma grande quantidade de escritos, não seria possível apresentar seu trabalho de maneira exaustiva. Para o presente artigo, foram selecionados dois pontos fundamentais de sua proposta, intentando expô-la de modo sucinto e demonstrar seus aspectos de pioneirismo.

\section{Construção de instrumentos}

Em um primeiro momento, o trabalho em estúdio particular com crianças pequenas estava centrado em canções, danças e brincadeiras. Entretanto, na medida em que as crianças se envolviam com essas atividades, demonstravam o desejo de também tocar o repertório relacionado. Por acreditar que os instrumentos tradicionalmente usados na iniciação de crianças à época não eram adequados - Coleman (1922) é categórica ao criticar o ensino de piano e violino na infância -, a educadora decidiu procurar instrumentos de execução mais simples. Não encontrando nada que julgasse satisfatório, Coleman começou a construir, ela mesma, instrumentos para usar em aula e, ao fazê-lo, percebeu que as próprias crianças seriam capazes de construí-los. Os alunos de cinco a nove anos de idade começaram, então, a construir instrumentos de percussão, cordas e sopro, enquanto, aos menores, abria-se a possibilidade da prática instrumental. Baseio-me, neste artigo, principalmente nos relatos do livro Creative Music for Children (1922), mas esse assunto é corriqueiro na obra da educadora. Ele é invocado, por exemplo, no livro A children's symphony (1931), pois na orquestra escolar havia instrumentos artesanais, e em Your child's music (1939), onde pais e mães são orientados a construírem instrumentos em casa junto às crianças, dentre outras obras.

Os instrumentos eram construídos e usados pelas crianças sem organização em sequência prévia, apesar de aparecerem agrupados em famílias no livro de 1922. A educadora (1922) apenas salientou que os sopros apresentam maior dificuldade e que o fator que guiava a escolha não era uma lista de categorias ou o desenvolvimento histórico, e sim a simplicidade. Para orientar as atividades de construção, eram feitas 
pesquisas sobre instrumentos de várias culturas, tanto pela leitura de livros quanto pela visitação a museus.

Os relatos dos processos de construção mostram que havia abertura para a iniciativa das crianças, como quando se inicia a pesquisa acerca dos instrumentos de sopro e a autora relata que "da mesma maneira que eles experimentaram bater em tudo anteriormente, agora eles tentam soprar qualquer coisa que possa ser soprada, e seus experimentos são reveladores" (Coleman, 1922, p. 52-53). As atividades não se restringiam à cópia de instrumentos já existentes, abrangendo também instrumentos inventados ou descobertos pelos próprios alunos, como nas duas passagens a seguir:

[...] uma criança trouxe para mim um instrumento que ela mesma inventou. Este consistia em três colheres de prata de diferentes tamanhos, suspensas por cordas de uma base de madeira. Batendo nessas colheres suspensas, a criança tocou uma melodia para mim (Coleman, 1922, p. 44).

Um dia, Florence trouxe a mim, com muito orgulho, um instrumento que ela descobriu e que não era de sopro, nem de cordas ou de percussão. Era um grande cacto espinhoso que cresceu em um vaso da janela de sua mãe. Ela descobriu que os espinhos longos vibravam e soavam musicalmente quando ela os fazia vibrar, e que produziam notas diferentes. Testando-os de maneira cautelosa, ela encontrou três espinhos que se aproximavam das três primeiras notas da escala. Então, orgulhosamente, tocou uma verdadeira melodia para mim no cacto! Que ótima prova de que o mundo - mesmo os prados inférteis do oeste - é rico em possibilidades musicais, basta que tenhamos olhos para ver e ouvidos para ouvir! (Coleman, 1922, p. 49).

Há ainda relatos referentes a situações em que as crianças trazem materiais inusitados para o estúdio com vistas a transformá-los em instrumentos, como quando constroem harpas com ossos e galhos de árvores; ou em que conhecimentos de acústica são testados e elaborados de acordo com o uso experimental dos materiais, como quando uma criança descobre as variações de altura possibilitadas pela manipulação de um cavalete móvel, ou das variações de ressonância geradas pelo contato do instrumento com diferentes superfícies.

A centralidade das atividades de construção de instrumentos na Creative Music diz respeito a alguns aspectos caros ao movimento pedagógico do qual fazia parte, a Progressive Education. A valorização dos trabalhos manuais estava em voga nas mais diversas disciplinas, em uma busca por processos de aprendizagem mais ativos. Além do acento nos trabalhos manuais, os relatos demonstram que a educação musical assim orientada estava também conectada a outros princípios pedagógicos progressistas, como o learning by doing - aprender fazendo -, evidente no 
engajamento relatado nas pesquisas para a construção e na verificação das propriedades físicas dos materiais manipulados.

Southcott (2009), em artigo onde trata das referências de Coleman, observa que o termo experiência é usado pela educadora desde seus primeiros escritos em uma perspectiva deweyana. Branco (2010), ao se dedicar ao conceito de experiência educativa em Dewey, indica duas características elementares desta: a continuidade e a interação. A continuidade estaria ligada ao aspecto temporal, já que uma experiência educativa sempre se funda em experiências precedentes e condiciona aquelas que a seguem, estabelecendo condições de continuidade. A interação, por sua vez, estaria ligada ao aspecto espacial, dizendo respeito às relações entre o organismo e o meio que o circunda. Branco (2010) ainda destaca que a experiência educativa em Dewey é resultado de uma combinação entre atividade e passividade, pois, em um processo educativo, a criança faz uma experiência e sofre suas consequências, de modo que a atuação e a mudança engendrada necessitam ser refletidas. Para Alix (2017), a experiência educativa em Dewey tem caráter de continuidade no que tange às conexões entre as experiências das crianças e as experiências da humanidade. Alix (2017) aponta que, na teoria deweyana, experiências individuais infantis e aquelas acumuladas na cultura social, tal como estruturam o programa escolar, unem-se em um processo contínuo de civilização.

Um relato elaborado por Coleman (1922) sobre Elizabeth, a primeira aluna que decide construir um violino, pode ser interpretado como exemplo dos desdobramentos que as ideias sobre experiência educativa em Dewey encontraram na prática de educação musical orientada pela Creative Music. $\mathrm{Na}$ seção dedicada aos instrumentos de cordas friccionadas, lemos que, em um primeiro momento, estes eram construídos sempre para serem tocados no colo ou entre as pernas, como violoncelos, visando à facilidade de execução. Elizabeth - cuja idade não nos é informada, mas que tinha certamente entre cinco e nove anos de idade de acordo com a descrição do trabalho desenvolvido no estúdio - toma a iniciativa de construir um violino e o faz, orientada por Coleman. Como nos instrumentos construídos até então, foram adicionadas apenas três cordas, também para facilitar a execução. Após a construção, a educadora (Coleman, 1922) conta que o uso do arco e do instrumento foram facilmente adaptados à nova posição. Este novo instrumento serviu de modelo para que outras crianças também construíssem violinos e os incorporassem em suas práticas de música de câmara. Alguns meses depois, Elizabeth foi presenteada com um violino convencionalmente fabricado e a importância deste momento, bem como sua relação com a experiência de construção, é assim relatada por Coleman:

Depois de alguns meses de uso de um violino artesanal, Papai Noel trouxe para Elizabeth um violino "de verdade", e esse foi um ponto importante de seu desenvolvimento 
musical. Ela agora possuía um violino de fabricação profissional em suas mãos pela primeira vez na vida, e ele parecia um velho amigo muito próximo. Ela não apenas sabia os motivos de cada pequeno detalhe de sua construção, como também estava apta a apreciar todas as vantagens deste em relação ao seu instrumento rudimentar: seu polimento fino, suas curvas graciosas e, principalmente, as laterais cavadas onde o arco poderia correr livremente. $\mathrm{O}$ instrumento adequou-se naturalmente sob seu queixo e quando ela passou o arco pelas cordas pela primeira vez, estava consciente da riqueza sonora que ela não era apta a produzir até então, e se maravilhou com as habilidades de um luthier profissional. Ela possuía uma carga de conhecimento e experiência que a permitia apreciar de uma só vez a riqueza de timbre e as grandes possibilidades musicais, e discriminar entre suas próprias notas boas ou más. Mesmo que apenas um bom violino "de verdade" e bem fabricado possa agora atender às suas necessidades musicais, ela ainda guarda afeição pelo objeto que ela mesma construiu - seu primeiro pequeno violino (Coleman, 1922, p. 78-79).

O caso de Elizabeth é exemplar em muitos aspectos. A construção de seu violino é um desdobramento de experiências anteriores - visto que o grupo já vinha construindo instrumentos de cordas friccionadas, porém maiores e tocados em outra posição -, um desdobramento desafiador na medida em que adiciona complexidade ao que já vinha sendo desenvolvido, conferindo continuidade. A família de cordas, ao ser enriquecida com um novo instrumento, muda a qualidade da interação entre as crianças ao atribuir novidade em sua prática de música de câmara. Por fim, o processo de construção e o uso do instrumento artesanal permitiram à Elizabeth aceder a uma relação mais complexa e informada com o violino profissional. A continuidade entre seu processo de aprendizagem e as experiências acumuladas socialmente se mostra na compreensão que a menina pode ter deste objeto da cultura, suas qualidades e as razões que determinam suas características.

Levando-se em consideração todas as críticas que Coleman faz ao ensino indiscriminado de violino na infância, o caso de Elizabeth é, ainda, prova de que as observações da educadora sobre a prática instrumental das crianças não são asserções a serem seguidas de maneira rígida. O relato trata do uso do violino em um caso no qual a orientação pedagógica relacionada à postura ativa da aluna possibilitou um processo significativo de construção de conhecimentos musicais e de habilidades motoras. Este caso nos leva a outro aspecto central da Creative Music, a saber: as práticas criativas. Em meio às composições feitas pelas crianças, encontra-se uma de título "Uma dança para o novo violino" assinada por Elizabeth. A importância das atividades de criação é o tema da próxima seção. 


\section{Práticas criativas}

Como exposto anteriormente, as crianças tiveram espaço e iniciativa para inventar instrumentos, ainda que este não fosse o foco da proposta pedagógica, sendo essas invenções relatadas com ares de excepcionalidade. $\mathrm{O}$ incentivo às práticas criativas na Creative Music se mostra de maneira mais evidente nas passagens dos escritos de Coleman em que são abordadas as atividades de composição e improvisação, bem como nos indícios da valorização dos produtos das criações infantis.

Tanto a composição quanto a improvisação são tomadas como práticas a serem incentivadas desde a infância, sem dependência de talento especial ou conhecimentos teóricos avançados. Em Your child's music (1939), livro dedicado às famílias, vê-se que a educadora aconselha as mães a cultivarem o hábito de cantar melodias espontâneas para estimular a improvisação e a expressão vocal livre. Ela defende que as melodias improvisadas pelas crianças pequenas, por volta dos três anos de idade, sejam chamadas de "melodias acidentais" (Coleman, 1939, p. 43), pois têm a particularidade de serem resultado de uma ação descomprometida com a manutenção do produto e, por vezes, ainda pouco atenta.

Considerando as crianças muito pequenas e também as maiores, a autora defende que as práticas criativas poderiam ser estimuladas de maneira corriqueira em casa. Ela apresenta sugestões como a criação de canções sobre as flores por ocasião de um passeio no jardim ou a composição de uma canção de aniversário para membros da família. As invenções ao instrumento também deveriam ser encorajadas desde o início do contato com o objeto, ao que Coleman (1939) especifica como única condição o conhecimento do uso adequado do instrumento, de maneira que sua utilização seja propriamente musical.

No livro A children's symphony (1931), a composição de pequenos temas pelas crianças deu origem à Sinfonia $n^{\circ} 3$. Além de relatar aspectos da criação no ambiente escolar, como as escolhas formais feitas no processo e a escolha de tonalidade de acordo com os instrumentos que estavam sendo construídos por uma turma, Coleman (1931) também expõe depoimentos das crianças envolvidas e de seus pais e mães. Segundo a autora (1939), tanto em questionários quanto em conversas informais, os responsáveis declararam que seus filhos e filhas passaram a improvisar e compor melodias em casa influenciados pelo projeto escolar.

A importância das atividades criativas na Creative Music estava em evidência já no início do trabalho em estúdio particular, como Coleman mostra em seu primeiro livro, ao tratar da composição como prática necessária desde o início dos estudos musicais:

compor tem sido uma atividade definitivamente estabelecida em cada fase do trabalho. Acredito que a habilidade do pensamento e da ação original é melhor incentivada nos 
primeiros estágios de qualquer forma de expressão, pois após o estabelecimento completo de hábitos de seguir linhas convencionais, torna-se muito dificil para uma pessoa comum mudar de conduta em direção a caminhos novos (Coleman, 1922, p. 122).

Também a prática da improvisação aparece como hábito a ser fomentado, quando Coleman (1922) nega que esta seria exclusividade de pessoas naturalmente inclinadas:

acredito que a improvisação, assim como o canto e outras
habilidades que muitas pessoas consideram dons especiais,
são o resultado de hábitos cultivados desde cedo; e a criança
que começa a improvisar canções, danças e melodias
instrumentais já nos primeiros estágios de seu
desenvolvimento musical, crescerá naturalmente nesta
direção, como uma flor que vai em direção ao sol, porque a
alegria que ela experimenta com o trabalho original é o
estímulo necessário (Coleman, 1922, p. 175-176).

No livro Creative Music for Children (1922), além da defesa das duas práticas nas passagens citadas acima, observa-se também que a educadora as considerava de maneira distinta. A improvisação aparece como prática por excelência no início da infância, como quando a autora afirma que "para as crianças muito pequenas, improvisar é muito mais fácil que aprender uma dada melodia" e que "todas as crianças amam fazer isso" (Coleman, 1922 , p. 176). Em exemplos, a autora sugere que, entre seus alunos menores - o trabalho começava aos três anos de idade -, essa prática tem especificidades como a concomitância de improviso em melodia e letra ou música e dança, e é correntemente "sem forma" (Coleman, 1922, p. 128), argumentando que estas são características da expressão artística de crianças pequenas.

Para as crianças maiores, contudo, a improvisação aparece como etapa do processo composicional. É notável, por exemplo, que o título do capítulo que trata do tema no livro em questão seja Composições Originais - e não, por exemplo, Criações -, o que corrobora a ideia de que, na Creative Music, a composição ganharia mais destaque que a prática de música improvisada à medida que as crianças crescem. Em exemplos de processos criativos, Coleman (1922) considera que o fato de tocar ou cantar uma frase e não lembrá-la perfeitamente logo em seguida é uma dificuldade a ser superada. A educação musical assim orientada parece acompanhar uma necessidade, através da atividade das crianças, de desdobramento material. O resultado da postura ativa dos alunos seria tanto a construção de seus próprios instrumentos quanto a composição de suas próprias músicas.

Observamos que, apesar de salientar que o foco dessa abordagem é o desenvolvimento musical, como quando destaca que "a compensação da professora é ver o efeito na criança, não na beleza intrínseca do que foi 
criado" (Coleman, 1922, p. 209, grifo no original), os produtos das atividades de criação são também valorizados. Muito antes do trabalho sobre a composição da Sinfonia $n^{\circ} 3$ em A children's symphony (1931), onde isso é evidente, as criações das crianças já aparecem com destaque nos relatos do trabalho em estúdio particular. No capítulo "Composições Originais" do livro de 1922, constam dois programas de eventos realizados no Creative Music Studio, já situado em Nova York, nos anos de 1920 e 1921. Ambos os programas são constituídos inteiramente de composições originais e improvisações, e várias destas criações são tocadas em instrumentos artesanais. Nos programas de trabalho desenvolvidos na disciplina Creative Music da Lincoln School (Columbia University, 1922), também constam composições individuais e coletivas, bem como indicações de instrumentos inventados por crianças.

A ênfase nas atividades criativas defendida por Coleman em seus escritos e realizada em sua prática pedagógica não era consenso no contexto em que estava inserida, como já apontamos aqui. Sobre as atividades específicas de construção de instrumentos e composição, a seguinte passagem é exemplar da natureza de críticas endereçadas à Creative Music:

\begin{abstract}
Por vezes as escolas parecem considerar que o termo [creative expression] significa apenas trabalho original, seja na forma de melodias compostas pelas crianças ou instrumentos construídos por elas. Mesmo que isso seja, em algum sentido, criativo, penso que é um erro grave evidenciálos como vem sendo feito em algumas escolas. Isso é um erro porque nenhum desses projetos é importante no treinamento da criança em música, e porque ambos tomam muito tempo. Todos os momentos de um programa de música liberal poderiam ser empregados de maneira proveitosa ensinando música de verdade para as crianças e desenvolvendo suas habilidades para isso (Surette, 1932, p. 69, grifos nossos).
\end{abstract}

Trata-se de passagem de artigo de Thomas Surette, outro educador musical de destacada atuação na associação Progressive Education. Surette (1930, 1932), além de direcionar suas críticas à abertura para a participação criativa das crianças, operava também, neste cenário e em contraponto à Creative Music, uma defesa da educação pelo canto, contrariando o incentivo à construção e prática instrumental na infância representada por Coleman.

A existência de críticas como a de Thomas Surette e a difusão nacional e internacional da Creative Music, observada através da profusa produção de Coleman e da sua presença na imprensa pedagógica à época, dá a ver o protagonismo alcançado pela educadora. Sua coerência no contexto da Progressive Education e, de maneira mais ampla, nos movimentos pedagógicos internacionais, pode ser compreendida por traços epistemológicos de seu trabalho e pela sua atuação institucional, temas da seção seguinte. 


\section{Coleman e seu CONTEXTO: CREative MUSiC COMO EduCAÇÃo MUSICAL PROGRESSISTA}

Fundado em 1887, o Teachers College (TC) da Columbia University passou a contar com um instituto internacional em $1923^{5}$, um ponto de encontro de educadores em formação de inúmeros países, dentre os quais, o brasileiro mais célebre foi Anísio Teixeira. Além de ser visitado por educadores de origens diversas, serviu de modelo para a fundação de outros estabelecimentos de formação de professores (Vidal; Rabelo, 2019). Na primeira metade do século XX, o TC se firmava como referência para a educação progressista pela posição destacada no trânsito internacional, bem como pela existência da Lincoln School, escola-laboratório onde as propostas de revisão curricular e didática eram experimentadas. Foi nessas instituições que Coleman desenvolveu seu trabalho junto a crianças e professores por mais de duas décadas.

Em apresentação de G. Stanley Hall ao livro Creative Music for Children (1922), um texto curto e elogioso, a abordagem de Coleman é situada em um ambiente teórico predominantemente marcado pela Teoria da Recapitulação. Segundo Alix (2017), ainda que os progressistas tenham aderido massivamente a este principio, suas conclusões pedagógicas foram plurais e mesmo discordantes nas prescrições sobre aspectos como a organização de conteúdos escolares, o papel do educador, entre outros. Acerca do pensamento pedagógico do próprio Stanley Hall, Alix afirma que

Essa pedagogia tem por principio organizador, ou
arquitetônico, a teoria da recapitulação: a ideia segundo a
qual a criança, no curso de seu desenvolvimento, passa por
uma série de estágios que foram percorridos pela
humanidade ao longo da história. Nessa perspectiva, a
educação ou o ensino escolar deve respeitar estritamente os
estágios de desenvolvimento da criança tal como a psicologia
genética permite discernir (Alix, 2017, p. 108, grifo no
original).

Embora Hall (in Coleman, 1922) declare que a Creative Music seria a melhor realização dessa ideia, Coleman (1922) não se compromete com tal fundamento, esquivando-se de tratar a educação musical de crianças diretamente sob essa perspectiva quando esclarece que seu trabalho "não intenta fundamentar ou discutir a popular Teoria da Recapitulação" (Coleman, 1922, p. 143). No entanto, a autora não está alheia ao quadro epistemológico. Sua obra é constantemente marcada por comparações entre as crianças e o homem primitivo, o que se conecta com a forte presença da teoria evolucionista de Herbert Spencer nos Estados Unidos desde a segunda metade do século XIX (Alix, 2017). A leitura contemporânea de tal material reconhece, na comparação etnocêntrica que equipara crianças

\footnotetext{
${ }^{5}$ Fonte: https://www.tc.columbia.edu/about/history/
} 
ocidentais a um suposto estágio cultural de nivel inferior de outros povos, um "pecado antropológico" (Lévi-Strauss, 1952) próprio do período e do qual Coleman não escapa.

Southcott (2009) encontra, na obra de Coleman e na educação musical do início do século $\mathrm{XX}$ de maneira mais ampla, ecos dos debates evolucionistas em música também da segunda metade do século XIX. As hipóteses e teorias elaboradas sobre a origem e a evolução da música assumiram caráter didático ao se transpor, para o âmbito da educação, a sequência percussão - sopros - cordas ou, em outros termos, o itinerário ritmo - melodia - harmonia. Mesmo depois da superação do quadro teórico evolucionista, Southcott (2009) indica que alguns desses pressupostos persistem e são encontrados conferindo ordem em materiais modernos de educação musical, ainda que de maneira menos ingênua.

As comparações entre crianças e o homem primitivo, embora evidenciem uma visão antropológica equivocada, têm como consequência o reconhecimento de repertórios não ocidentais em ambiente educativo orientado pela Creative Music. Ainda que não seja possivel equiparar às discussões posteriores sobre o assunto, Volk (1996) avalia que um espaço significativo estava em vias de se abrir na educação musical

Nas definições atuais, Satis Coleman não era uma educadora de world music. Seus objetivos com a construção de instrumentos eram baseados em caminhos para promover a criatividade musical de seus alunos. [...] Coleman contribuiu, no entanto, para o nosso conhecimento de maneiras pelas quais o multiculturalismo musical pode ser introduzido em sala de aula. Neste sentido, sua metodologia da creative music continha precursores da educação para a world music (Volk, 1996, p. 33).

Apesar de concordar com a ampliação de repertório, mesmo que em cenário contraditório, indicada por Volk (1996), faz-se necessário atentar para o termo metodologia na citação acima, salientando que Coleman esclarece repetidas vezes em seus escritos que a Creative Music não é um método, e sim uma proposta pedagógica que se funda em postura experimental (1922, 1932, 1932/1933). Se a autora documentou e divulgou aspectos de sua atuação educativa, o fez, segundo ela (1922), com vistas a auxiliar adultos que queiram fazer uso prático de tal material, defendendo que a ação pedagógica é pessoal e depende do educador e das circunstâncias.

O quadro epistemológico evolucionista, a postura pedagógica experimental, o pioneirismo na abertura para a participação das crianças, a assunção dos trabalhos na Columbia University e sua difusão internacional são todos aspectos que mostram Satis Coleman no cerne do pensamento pedagógico renovador - no caso dos Estados Unidos, protagonizado pela 
associação Progressive Education - e sua Creative Music como o desdobramento central de tal pensamento no âmbito da educação musical.

\section{CONSIDERAÇÕES FINAIS}

Apesar das bases epistemológicas hoje passiveis de contestação, o estudo da Creative Music, bem como dos movimentos renovadores da primeira metade do século XX de maneira mais ampla, toca temas contemporâneos da educação. O incentivo à participação das crianças e a valorização de atividades criativas são assuntos presentes na literatura científica e em documentos oficiais, encontrando cada vez mais espaço nas práticas pedagógicas (Barrera, 2016; Brasil, 1997, 1998, 2018; Unesco, 2016). O pioneirismo do trabalho de Satis Coleman em tais assuntos evidencia-se com a análise de sua produção e de sua repercussão à época, visto que sua atuação se deu em instituição experimental destacada e suscitou adesão e crítica, movimentando debates na área.

Conhecer seu trabalho e a influência que teve à época nos leva a reavaliar o discurso historiográfico quando este trata das inovações didáticas em educação musical. De maneira geral, consideram-se os chamados métodos ativos como expoentes das proposições pedagógicas da área, um quadro predominantemente masculino, europeu, protagonizado por compositores e que teve como lócus prevalente escolas livres de música ou conservatórios. O estudo de propostas como a de Coleman e sua circulação internacional abrem espaço para questionamentos sobre as inovações engendradas por educadoras e educadores em diferentes países e em diferentes cenários. A Creative Music aponta, ainda, para a existência de propostas pedagógicas em educação musical ligadas a projetos educacionais mais amplos, conectando o ensino de música a aspectos gerais da educação.

No que concerne à superação de um quadro predominantemente masculino na história da educação musical, tem-se como exemplo, no Brasil, os trabalhos de Rocha (2012, 2017), quando investiga a trajetória de Liddy Chiaffarelli Mignone, e de Igayara-Souza (2011), quando se dedica à produção brasileira escrita por mulheres sobre música e educação musical na primeira metade do século XX. Acrescentamos, ainda, que diversos outros esforços vêm sendo empreendidos de maneira a contemplar o protagonismo de mulheres na história da educação (Vidal; Vicentini, 2019) e na musicologia (Nogueira; Fonseca, 2013).

Em relação ao presente artigo, reconhecendo com Volk (1996), Southcott (1990, 2009) e Shevock (2015) que a análise do trabalho de Coleman contribui para a educação musical além de seu tempo, intentou-se lançar luz sobre seus aspectos de pioneirismo e coerência com o cenário no qual foi desenvolvido, além de fazê-lo mais conhecido, junto aos esforços de Caldeira Filho (1945; s.d.) na bibliografia brasileira. 


\section{REFERENCIAS}

ALIX, Sébastien-Akira. L'éducation progressiste aux États-Unis: histoire, philosophie et pratiques (1876-1919). Grénoble : PUG, 2017.

BARRERA, Tathyana Gouvêa da Silva. O movimento brasileiro de renovação educacional no início do século XXI. Tese (Doutorado em Educação) Faculdade de Educação, Universidade de São Paulo, São Paulo, 2016. doi: 10.11606/T.48.2016.tde-16082016-113432. Acesso em 9 set. 2019.

BRANCO, Maria Luísa. O sentido da educação democrática: revisitando o conceito de experiência educativa em John Dewey. Educação e Pesquisa, São Paulo, v. 36 n. 2, p. 599-610, maio/ago. 2010

BRASIL. Secretaria de Educação Fundamental. Parâmetros Curriculares Nacionais: Arte. Brasília: MEC/SEF, 1997.

BRASIL. Ministério de Educação e do Desporto. Secretaria de Educação Fundamental. Referencial curricular nacional para a educação infantil. vol. 3. Brasília: MEC/SEF, 1998.

BRASIL. Ministério da Educação. Base Nacional Comum Curricular. Brasília: MEC, 2018.

CALDEIRA FILHO, João. Música criadora e balladas de Chopin. 1. ed. São Paulo: L.G. Miranda, 1935; 2. ed. [s.d.].

CALDEIRA FILHO, João. Educação musical infantil. Revista Brasileira de Estudos Pedagógicos, vol. III, n. 7, p. 120-122, 1945.

COLEMAN, Satis N. Creative music for children. New York: Putnam, 1922.

COLEMAN, Satis N. A children's symphony: as developed in the Creative Music Classes of Lincoln School of Teachers College, with the themes composed entirely by the children, and played by them on instruments of their own making and other simple instruments. New York: Lincoln School of Teachers College, Columbia University, 1931.

COLEMAN, Satis N. Creative experience through making musical instruments In HARTMAN, Gertrude; SHUMAKER, Ann (Org.). Creative expression: the development of children in Art, Music, Literature and Dramatics. New York: The John Day Company, 1932, p. 91-98.

COLEMAN, Satis N. The progress of the movement for Creative Music. Progressive Education, New York, vol. X, p. 27-31, dec. 1932/jan. 1933.

COLEMAN, Satis N. Your child's music. New York: John Day Company, 1939.

COLUMBIA UNIVERSITY. The Lincoln School of Teachers College: a descriptive booklet. New York: The Lincoln School of Teachers College, 1922. 
DUSHKIN, David. Some experiments in music: the Glencoe Public Schools. Progressive Education, vol. VIII, p. 346-348, 1931.

DUSHKIN, David. An experiment in music education. Progressive Education, vol. XX, p. 144-149, 1933.

IGAYARA-SOUZA, Susana Cecilia Almeida. Entre palcos e páginas: a produção escrita por mulheres sobre música na história da educação musical no Brasil (1907-1958). Tese (Doutorado em Educação) - Faculdade de Educação, Universidade de São Paulo, São Paulo, 2011. doi:10.11606/T.48.2011.tde-04072011-145947. Acesso em 9 set. 2019.

LÉVI-STRAUSS, Claude. Race and history. Paris: Unesco, 1952.

NOGUEIRA, Isabel P.; FONSECA, Susan C. (Org.) Estudos de gênero, corpo e música: abordagens metodológicas. Goiânia/Porto Alegre: ANPPOM, 2013.

POTTER, Edith. Values in the use of instruments in school projects. Progressive Education, vol. VIII, p. 345-346, 1931.

POTTER, Edith. A children's symphony (resenha). Progressive Education, vol. IX, p. 527, 1932a.

POTTER, Edith. The development of musical consciousness in the young child. In HARTMAN, Gertrude; SHUMAKER, Ann (Org.). Creative expression: the development of children in Art, Music, Literature and Dramatics. New York: The John Day Company, 1932b, p. 116-124.

ROCHA, Inês de A. Canções de Amigo: redes de sociabilidade na correspondência de Liddy Chiaffarelli Mignone para Mário de Andrade. Rio de Janeiro: Faperj, 2012.

ROCHA, Inês de A. Modernidade e Modernismo na Iniciação Musical e nas práticas educativas de Liddy Chiaffarelli Mignone. Revista da ABEM, Londrina, v. 25, n. 39, p. 20-38, jul./dez. 2017.

SHEVOCK, Daniel J. Satis Coleman: a spiritual philosophy for Music Education. Music Educator Journal, v. 102, n.1, p. 56-61, 2015.

SOUTHCOTT, Jane. A music education pioneer: Satis Naronna Barton Coleman. British Journal of Music Education, v. 7, n.2, p. 123-132, jul. 1990.

SOUTHCOTT, Jane. The seeking attitude: ideas that influenced Satis Coleman. Journal of Historical Research in Music Education, v.31, n.1, p. 2036, 2009.

SURETTE, Thomas Whitney. Music teaching in schools. Progressive Education, vol. VII, n.3, p.107-114, 1930.

SURETTE, Thomas Whitney. A general view of music education for children. In HARTMAN, Gertrude; SHUMAKER, Ann (Org.). Creative expression: the 
development of children in Art, Music, Literature and Dramatics. New York: The John Day Company, 1932, p. 69-74.

UNESCO - United Nations. Educational, Scientific and Cultural Organization. Education for people and planet: creating sustainable futures for all. Global Education Monitoring Report. Paris, 2016.

VIDAL, Diana G.; RABELO, Rafaela S. A criação de Institutos de Educação no Brasil como parte de uma história conectada da formação de professores. Cadernos de História da Educação, v.18, n.1, p.208-220, jan./abr. 2019.

VIDAL, Diana G.; VICENTINI, Paula P. (Org.). Mulheres inovadoras no ensino: São Paulo, séculos XIX e XX. Belo Horizonte: Fino Traço, 2019.

VOLK, Terese M. Satis Coleman's Creative Music. Music Educators Journal, v. 82, n.6, p. 31-33, maio 1996.

Tamya Moreira é licenciada em Artes/Música pela Universidade Estadual de Campinas (Unicamp). É mestra e doutora em Artes/Música pela Universidade de São Paulo (USP), na linha de pesquisa Música e Educação: processos de criação, ensino e aprendizagem. Realizou estágio de pesquisa de doutorado na Université Paris 8 Vincennes - Saint Denis, França. Atualmente, é professora substituta no curso de Licenciatura em Música da Universidade Federal de São Carlos (UFSCar). https://orcid.org/0000-0002-8315-5651 